\title{
Relationship between Achievement Goals and Attention of University Instructors in Professional Training Courses
}

\author{
Benjamin Kücherer \\ University of Augsburg
}

\author{
Markus Dresel \\ University of Augsburg
}

\author{
Martin Daumiller \\ University of Augsburg
}

\begin{abstract}
Purpose
Professional training courses play an important role for higher education instructors and their teaching quality. However, participants strongly differ in how much they learn in these courses. The present study seeks to explain these differences by focusing on attention as a central aspect of their behavioral engagement that can stem from participants' achievement motivations.
\end{abstract}

\begin{abstract}
Design/methodology/approach
We investigated the attention of participants in full-day professional higher education training courses and how differences therein are associated with their achievement goals. Prior to course participation, 117 university instructors (49.6\% male, 79.5\% with Ph.D., average age 31.4 years) reported their achievement goals. Using an adapted observational instrument (Hommel, 2012b), two raters subsequently observed and coded the participants' attention during the course (ICC2 $=.83$ ).
\end{abstract}

\begin{abstract}
Findings
Our results documented very high attention levels, albeit with substantial interindividual differences. Multilevel analyses indicated that learning goals positively and work avoidance goals negatively predicted observed attention.

Originality/value

Our findings provide insight into the value of an observational approach to measuring a fundamental aspect of learning engagement, and contribute to the understanding of interindividual differences in an important higher education learning environment. The study illuminates the relevance of personal predictors for university instructors' successful learning. Specifically, our findings point to the significance of goals as a relevant, but surprisingly hitherto uninvestigated, premise of learning engagement.
\end{abstract}

Keywords: Achievement Goals, Attention, Professional Training, Observation, University Instructors

(C) 2020, Emerald. The official citation for this manuscript is: Kücherer, B., Dresel, M., \& Daumiller, M. (in press). Relationship between achievement goals and attention of university instructors in professional training courses. Higher Education, Skills and Work-based Learning. Advanced online publication. https://doi.org/10.1108/HESWBL-05-2020-0075. This paper is not the copy of record and may not exactly replicate the final, authoritative version of the article. The final article will be available, upon publication, via its DOI.

There is a constant need for learning and improvement throughout university instructors' careers (Neumann, 2009; Terosky and Gonzales, 2016), particularly as they often lack explicit didactical training (e.g., regard-

Correspondence concerning this article should be addressed to Martin Daumiller, Department of Psychology, University of Augsburg, Universitätsstr. 10, 86159 Augsburg, Germany; Martin.Daumiller@phil.uni-augasburg.de.

We have no known conflicts of interest to disclose.

The research reported in this article was supported by the German Research Foundation (Deutsche Forschungsgemeinschaft; DFG): Grant DR 454/8-1 awarded to Markus Dresel. ing new teaching methods; Daniels, 2017) and are frequently confronted with changing requirements (e.g., different topics and teaching formats; Gerken et al., 2015; Saroyan and Trigwell, 2015). The updating of instructional strategies and the acquisition of further didactical skills are essential for university instructors to improve their teaching (Svinicki and McKeachie, 2014; van Eekelen et al., 2005). Aside from informal learning activities such as talking with colleagues (Amundsen and Wilson, 2012; Gerken et al., 2015), professional training courses (e.g., in the form of single day courses during the semester or the semester break) concerning didactical skills constitute important formal learning 
activities for university instructors (van Eekelen et al., 2005; Saroyan and Trigwell, 2015).

Despite the well-documented importance of professional training courses (e.g. Webster-Wright, 2009), we know very little about how university instructors participate within them. Thadani et al. (2015) showed that implicit theories of university instructors' teaching skills have an impact on interest in professional learning. Moreover, in their review on university instructors' professional learning, Saroyan and Trigwell (2015) pointed out that substantial differences exist regarding the how much instructors learn in these courses. They emphasized that an important question that research on this topic should investigate involves factors that can explain interindividual differences, such as differences in their learning engagement. As an aspect of behavioral engagement (Fredericks et al., 2004), individual attention can be considered an important factor underlying differences in instructors' learning (Goleman, 2013). Previous research on secondary students suggests that learning success does not only stem from teachers providing high quality curriculum, but also from the learners themselves who-influenced by their motivation - decide how to use these learning opportunities and their attentiveness within them (Helmke, 2012). To this end, the relevance of attention has frequently been addressed in school contexts where it serves as a central explanatory variable for interindividual differences in learning success (e.g., Fisher et al., 1980; Hommel, 2012a; Savage and Savage, 2010). In particular, it can be expected to be associated with differences in students' motivations in the form of their goals (Moskowitz, 2002).

In the present research, we seek to illuminate differences in university instructors' learning by investigating their attention in professional training courses using an observational approach catered to the context of professional training courses (Hommel, 2012b). Based on prior research that investigated differences in university instructors' learning engagement as a function of their achievement goals (Daumiller et al., 2020a), we subsequently explored how differences in attention can be attributed to differences in instructors' achievement goals. This approach to motivation can be well embedded in the conceptual overview model of faculty motivation by Daumiller et al. (2020b). Within this, the authors illustrate that faculty motivation is characterized by an interplay of person-specific motivational tendencies (e.g., self-concept, motives) and contextual features (e.g., action demands and options) that matter for one's current motivation in a specific achievement situation (such as a professional training course). This motivation is, in turn, central to differences in engagement (and presumabily also attention levels) and, along with expectancy-beliefs, can be described by one's goals in a given situation. As such, by considering instructors' achievement goals, we focus on a central element of their specific motivations for professional training courses and examine the relevance of these goals for differences in attention therein.

\subsection{Relevance of Achievement Goals for Differences in University Instructors' Professional Learning}

Achievement goals constitute preferences for different end-states that an individual seeks to approach or avoid (Elliot, 2005; Hulleman et al., 2010). From the conception of Achievement Goal Theory, they have been considered as relevant personal factors for differences in individual learning behaviors (for an overview, see Korn et al., 2019). Regarding motivations for teaching, a common model of achievement goals distinguishes between learning approach (striving to develop and grow own competences), performance approach (striving to appear competent and surpass others), performance avoidance (striving to avoid appearing incompetent and to avoid doing worse than others), relational (striving to create good relationships with others), and work avoidance (striving to get though the day with little effort) goals (Butler, 2012; see also Daumiller et al., 2019 , for a conceptual overview model and further distinctions).

Strong learning approach goals have been shown to be associated with increased participation in further education courses (Hurtz and Williams, 2009; Nitsche et al., 2013a; Nitsche et al., 2013b), university instructors' planned participation in further education and their attitudes thereto (Diethert et al., 2015), university instructors' attitudes towards help seeking (Daumiller et al., 2019), their learning time (Hein et al., 2019), their own as well as their students' learning gains (Daumiller et al., 2016; Hein et al., 2019), and their selfreported learning effort, intensity, risk-taking, elaboration, implementation, and persistence in professional training courses (Daumiller et al., 2020a).

Performance approach goals typically portray a mixed effect pattern for learning processes in adults, including participation in didactical training courses (Nitsche et al., 2013a; Nitsche et al., 2013b), learning strategies (Senko and Dawson, 2016), and learning gains (Payne et al., 2007). In contrast, performance avoidance goals have been found to be linked to lower learning gains in general (e.g., learning success; Payne et al., 2007), negative attitudes towards continuing 
higher education didactical courses and lower participation in these opportunities in school teachers (Nitsche et al., 2013a; Nitsche et al., 2013b), as well as lower learning gains and unfavorable attitudes towards help-seeking in university instructors (Daumiller et al., 2019).

Finally, while relatively little is known about the relevance of relational goals for professional learning, work avoidance goals have been negatively linked to the number of attended continuing higher education didactical courses pursued by school teachers (Nitsche et $a l .$, 2013a), learning time and learning gains in university instructors (Daumiller, 2018), and their self-reported learning effort, intensity, and elaboration in professional training courses (Daumiller et al., 2020a).

Based on this research on adult learners, school teachers, and first insights into university instructors, achievement goals can be considered to be relevant for understanding differences in university instructors' learning behavior, particularly regarding their learning processes in professional training courses.

\subsection{Attention as a Relevant Behavioral Characteristic of Learning Engagement and its Assessment Through Observational Instruments}

As a process that selects action-relevant information and deselects irrelevant information, attention influences perception, action planning, and action execution. In consequence, attentional engagement can be defined as a process of intentional, sustained allocation of cognitive resources to guide problem solving, planning, sensemaking, and decision making (Ocasio, 2011). Within this, time, energy, and effort are focused on a selected set of environmental stimuli, repertoire of action responses, and the relationships between them (Ocasio, 1997).

Based on research on students, attention can be considered an important factor for successful learning. First, following an evaluative perspective, attention (aggregated at the class level) is often considered as a criterion variable (e.g., Rosenshine and Stevens, 1986). Second, from an explicative perspective, attention is considered to be an important aspect of individual school learning and achievement (Anderson, 1984), and is also reflected in learning models in schools, although different names are used for the term attention (e.g., "time on task", Helmke and Renkl, 1992; or "active learning time", Savage and Savage, 2010). Finally, in line with the teaching-learning processes perspective, multiple relevant components of attention can be identified (Imhof, 2004). In the present work, we focus on attention as a selection and focus process (e.g., Hommel, 2012b) that is often regarded as an important explanatory variable for interindividual differences for learning success (Fisher et al., 1980; Hommel, 2012b). These previous research works are limited in that they have primarily been conducted regarding the school context and have not been transferred to higher education. Nevertheless, given the underlying mechanisms of human learning and the role of attention in general memory models (Neumann, 1996), they also point to the relevance of university instructors' attention in professional learning courses. Furthermore, another limitation that pertains to many of the aforementioned research findings is that they have typically measured attention using self-reports. Self-reports are often criticized as they impair the validity of the assessments given that they rely on retrospective assessments and attention possibly not being consciously accessible (Helmke, 1988; Hommel, 2012b). To overcome these limitations, it has been argued that capturing attention using more objective approaches in the form of observation instruments may be beneficial (Helmke, 1988; Hommel, 2012b).

Concerning observing attention behavior, two established instruments exist for the school context. These include the Munich Attention Inventory (MAI, Helmke, 1988), which focuses on elementary schools, as well as a modified version for general schools, namely the ModAI (modified Munich Attention Inventory, Hommel, 2012b). The ModAI focuses on adolescents and adults in different phases of the classroom, taking a stronger, more learner-centered approach to teaching-learning processes. It divides attention behavior into two categories, "on-topic" (attention behavior as directed at the learning process) and "off-topic" (attention behavior as not directed at the learning process). This classification used by MAI and ModAI has been empirically supported as a sensible means of gaining insight into participants' attention behavior (e.g., Helmke and Schrader, 1998; Scholkmann et al., 2017). In the present research, we adapted the ModAI to capture university instructors' attention in professional training courses and examine the association with their achievement goals.

\subsection{Relevance of Achievement Goals for Attention during Learning}

As most attentive processes are driven by top-down concerns, personal factors can be considered to be important for their initiation and sustainment (Kasper and König, 2011). In particular, both the amount and the 
duration of attention devoted to incoming information is affected by active goals, with incoming relevant (vs. irrelevant) information for goal attainment being attended to much more (e.g., Gazzaley and Nobre, 2012). This is grounded in goals underlying engagement in volitional learning behavior. Goals define what individuals find desirable to attain and thereby what they strive for. The effects of goals on learning behaviors are consequently exerted by modulating attention (Csikszentmihalyi, 2018). When engaging in goal pursuit, individuals frequently face the challenge of remaining focused and at the same time, being flexible and adjusting their learning behaviors to adapt to changing circumstances (Dijksterhuis and Aarts, 2010).

As such, it can be expected that as achievement goal preferences make the corresponding goals salient, individuals should be more attentive to information that corresponds to their goals (Moskowitz, 2002). For example, a person who wants to thoroughly learn a certain topic (i.e., has strong learning approach goals), can be expected to pay more attention to that particular topic than to other topics (e.g., Aarts et al., 2001), while the contrary might be assumed for individuals with strong work avoidance goals.

Previous research has documented that learning approach goals facilitate deep-level processing and self-focus whereas performance approach goals and performance avoidance goals facilitate surface-level processing (e.g., Crouzevialle and Butera, 2013; Elliot, 1999; Murayama and Elliot, 2011; Nolen, 1988). Furthermore, learning approach goals allocate attention chiefly directed at the resolution of the task while individuals who strongly pursue performance goals tend to share attention between the task and concern about perceived performance and the achieved outcomes (Elliott and Dweck, 1988), resulting in more superficial processing of the task (Nolen, 1988; Darnon et al., 2007). Similarly, for work avoidance goals, a more superficial processing of the task can be expected as an attempt to save resources. Likewise, relational goals might orientate individuals on social interactions with others and simultaneously reduce their attention on the learning content at hand. Given these considerations, we therefore expected learning approach goals to go along with increased on-task attention, and performance approach, performance avoidance, work avoidance, and relational goals to go along with less on-task attentions. Surprisingly, however, this link between achievement goals and attention, as a very basic premise for initiating and sustaining learning processes, has hardly been empirically addressed in past research.

\subsection{Research Questions and Hypotheses}

In the present study we wanted to examine differences in university instructors' attention during professional training courses and how these differences can be explained by their achievement goals. Based on the considerations presented above, we expected substantial differences between instructors in their attention, and that these are related to instructors' achievement goals prior to course participation. Building on the aforementioned findings of previous research (e.g., Daumiller $e t$ al., 2016; Hein et al., 2019; Hurtz and Williams, 2009; Nitsche et al., 2013a; Nitsche et al., 2013b; Payne et $a l ., 2007)$, we hypothesized that learning approach goals are positively associated with attention and performance approach, performance avoidance, relational, and work avoidance goals are negatively associated with attention.

\section{Method}

To answer our research questions, university instructors were systematically observed by two observers in full-day professional training courses, prior to which the instructors made assessments regarding their achievement goals.

\subsection{Procedure and Sample}

The sample consisted of 117 participants from Germany (all were higher education faculty with teaching duties: six graduated with a Bachelor's degree, 81 with a Master's degree, 24 with a $\mathrm{PhD}$, three full professors), of which $49.6 \%$ were male. Their ages ranged between 21 and 54 years $(M=31.44$ years, $S D=7.17)$. They worked in 35 different subject fields (e.g., mathematics, law, business administration, pedagogy, geography, or art history) and were observed in 14 different courses (different in regard to the learning content, teaching methodology, and instructors; average participants per course: $M=9.1, S D=2.2$, Range: $4-12$ ) during a six month period. Active participation in the course was the prerequisite for successfully completing this course. It is important to note that university instructors in Germany are often required to teach in addition to their research activities. To support teaching competences, many universities offer voluntary professional training courses that are supported and promoted by most departments (as in our study). Instructors are typically not required to participate in these courses as an aspect of maintaining their employment status or for promotion, but rather as a voluntary endeauver (see Wosnitza et al., 
2013, for a more detailed description of the faculty working situation at German universities). Topics of the professional training courses included, for example, dealing with professional heterogeneity, blended learning, and counselling students. Participants' teaching experience ranged from one to 40 semesters $(M=6.9$, $S D=7.3)$, and they attended between one and 30 courses $(M=5.6, S D=4.2)$.

Prior to the start of the course, the participants were informed about the study. Immediately before the beginning of the course, the two observers explained the purpose and the procedure of the study in detail, after which the participants provided informed consent. Full anonymity of participants was ensured. Following this, the two observers asked the participants to complete a short questionnaire about their achievement goals and subsequently resided in the back of the room where they stayed during the entire course to ensure minimal disruption.

\subsection{Measurements}

\subsubsection{Achievement Goals}

Each achievement goal was measured with the academic achievement goal scale by Daumiller et al. (2019). Based on an item stem directed at the course at hand ("In this professional training course ..."), we measured their current learning approach (e.g., "...I want to constantly improve my competences", internal consistency: $\omega_{\mathrm{H}}=.88$ ), performance approach[1] (e.g., "...I want other colleagues to notice how good I am as an instructor", $\omega_{\mathrm{H}}=.96$ ), performance avoidance (e.g., "...I want to avoid other colleagues thinking that I am a bad instructor", $\omega_{\mathrm{H}}=.96$ ), relational (e.g., "...it is important to me to achieve a personal connection with colleagues", $\omega_{\mathrm{H}}=.90$ ) and work avoidance goals (e.g., "...it is important to me to have little to do", $\left.\omega_{\mathrm{H}}=.99\right)$ with four items each that were to be answered on a Likert-type scale ranging from 1 (do not agree at all) to 8 (agree completely).

\subsubsection{Observed Attention}

For this study, we slightly adapted the observation instruments of Helmke (MAI; 1988) and Hommel (ModAI; 2012b) to the context of adult education (by changing the coding length and adapting the description of the categories). At an average of ten times during the day $(M=10.1, S D=3.0)$, the observers conducted a systematic observation of all participants, each of them forming an observation cycle. They were selected in an approximately equally spaced order throughout the day, during theoretical phases or phases in the style of the frontal lessons (i.e., not during group work activities). In order to yield better reliability, each observation cycle in turn consisted of five passes during which all of the participants were observed. This was enforced using an audio signal that, depending on the number of participants in the room, signalled to the observers which participant they should observe and when to switch to the next participant. The length of each turn was previously determined. In the MAI, five seconds are given per observation interval, and $20 \mathrm{sec}-$ onds in the ModAI. Based on a pre-test in a piloting study with 8 participants, we set the coding interval of the current study at ten seconds as a sufficiently large value to reliably code the participants' attention. During each turn, attention was systematically assessed by the two observers (research assistants who were trained in advance based on the pre-test in the piloting study) using five categories. These distinguished between "active/self-initiated", "passive (inclusive reactive)", and "other subject-related attention behaviors" that counted as on-task behavior as well as "passive/not disturbing" and "active/disturbing" that were classified as off-task behavior. If a subject could not be coded with the previously described categories or the person in question was currently not observable, a missing value was entered. The inter-rater reliability was determined at this level and was interpreted as high (ICC2 $=.83$ ).[2] As in the MAI, the scores of each participant were dichotomized into on-task vs off-task and aggregated on the level of the observation cycles.

\subsection{Analyses}

For data analysis, we used Mplus 8.0 (Muthén and Muthén, 2017) using the maximum likelihood estimation with robust standard errors (MLR) to account for not all variables being normally distributed (as also reflected in their skew, see Tabel I). In total, we analyzed 918 observation cycles in 117 university instructors and controlled for the instructors having participated in 14 different courses (type $=$ twolevel complex). Taking the nested structure of the data into account (multiple attention cycles nested within instructors), we calculated a two-level regression model. Therein, we examined how stable differences between the instructors in their attention could be attributed to differences in their achievement goals. 
Table I Descriptive Statistics and Bivariate Correlations for Achievement Goals and Attention

\begin{tabular}{|c|c|c|c|c|c|c|c|c|c|c|}
\hline & \multirow[b]{2}{*}{$M$} & \multirow[b]{2}{*}{$S D$} & \multirow[b]{2}{*}{ Skew } & \multicolumn{2}{|c|}{ Range } & \multicolumn{5}{|c|}{ Bivariate correlations } \\
\hline & & & & Potential & Actual & 1 & 2 & 3 & 4 & 5 \\
\hline \multicolumn{11}{|l|}{ Between-person level } \\
\hline 1. Learning approach goals & 7.49 & $0.77 * * *$ & -3.04 & $1-8$ & $2.50-8.00$ & & & & & \\
\hline 2. Performance approach goals & 4.20 & $1.93 * * *$ & -0.06 & $1-8$ & $1.00-8.00$ & .10 & & & & \\
\hline 3. Performance avoidance goals & 4.43 & $1.90 * * *$ & -0.11 & $1-8$ & $1.00-8.00$ & .14 & $.67^{* * * *}$ & & & \\
\hline 4. Relational goals & 4.74 & $1.87 * * *$ & -0.24 & $1-8$ & $1.00-8.00$ & $.35 * * *$ & $.40^{* * * *}$ & $.30 * * *$ & & \\
\hline 5. Work avoidance goals & 2.83 & $2.02 * * *$ & 0.93 & $1-8$ & $1.00-8.00$ & $-.45^{* * * *}$ & .01 & -.02 & $-.21 *$ & \\
\hline \multicolumn{11}{|l|}{ Within-person level } \\
\hline 6. Attention ( $0=$ off-task, $1=$ on task $)$ & 0.90 & $0.14 * *$ & -1.37 & $0-1$ & $0.44-1.00$ & $.13^{*}$ & -.04 & .07 & .03 & $-.24 * *$ \\
\hline
\end{tabular}

Note. 918 observation cycles of attention in 117 university instructors. We additionally tested all standard deviations against zero. ${ }^{*} p<.05 . * * p .01 . * * p<.001$.

\section{Results}

Descriptively (Table I), we observed high levels of attention. Despite this, the observed attention differed statistically significantly between the different observation cycles. We analyzed these differences further by calculating intra-class-correlations (describing how similar observation cycles are within the same instructors and within the same courses). The results indicated that differences in attention could be substantially attributed to differences between different instructors $($ ICC instructor $=.13)$, while an additional inclusion of the course level did not account for further fractions of this variability (ICC course <.01). Thus, differences in attention can partially be traced back to different intructors, but not to different professional training courses.

Results of the two-level model (Table II) showed that instructors' learning approach goals at the beginning of the course positively and statistically significantly predicted their attention in the observed cycles during the course. This means that the stronger their learning approach goals were at the beginning of the course, the greater their attention was throughout. Conversely, work avoidance goals were negatively and statistically significantly related to observed attention.
This implies that the stronger the instructors' work avoidance goals were, the lower their observed attention levels were. Opposed to that, we did not find statistically significant effects for performance approach, performance avoidance, and relational goals. The findings of these two-level analyses were very similar to the biviarate correlations between the respective variables, which speaks to the robustness of the results (e.g., against suppressor effects).

\section{Discussion and Conclusion}

In the present study, we examined the attention of university instructors in professional training courses. To this end, we adapted an observational instrument to the professional training context and found high attention levels with substantial variance that could be attributed to differences between different instructors, particularly in their learning approach goals (positive effect) and work avoidance goals (negative effect).

The methodological approach of the present research is grounded in limitations of previous research that frequently relied on self-reports to assess attention (e.g., Baer et al., 2004), which are often criticized as

Table II Results of the Two-level Model on the Associations Between Achievement Goals and Attention Behavior

\begin{tabular}{lc}
\hline & $\beta(S E)$ \\
\hline Achievement goals (between-person level) & \\
Learning approach goals & $.25^{*}(.15)$ \\
Performance approach goals & $-.18 \quad(.17)$ \\
Performance avoidance goals & $18 \quad(.15)$ \\
Relational goals & $-.11 \quad(.15)$ \\
Work avoidance goals & $-.33^{* *}(.13)$ \\
$R^{2}$ & .23 \\
\hline Note. $N=918$ observation cycles of attention in $N=117$ university instructors. Presented are \\
standardized coefficients with standard errors. Significant parameters are presented in bold. \\
${ }^{*} p<.05 .{ }^{* *} p<.01$.
\end{tabular}


being biased (e.g., Dodd-McCue and Tartaglia, 2010; Hessing et al., 1988). Therefore, we adapted an observer instrument from the school context for the professional training context and found that it encompassed a reliable measurement by use of two trained observers. Further, the participants of the professional training courses reported that they did not feel disturbed by the two observers, which speaks to the merits of this approach. The statistically significant differences that we found in the participants' attention during the courses further attests that this approach can show differences in learning engagement during the course. However, the fact that these differences were rather small and at the same time, very high levels of attention were observed on the mean level, indicates that only a restricted range of differences in participants' learning engagement was modeled. This might be attributed to systemic differences between students in schools and university instructors in professional training courses. Most notably, opposed to students in schools, university instructors usually decide to participate in professional training courses voluntarily and are highly motivated (as also reflected in the strong learning approach goals that we observed). Furthermore, university instructors already successfully underwent nearly all available levels of formal education and are socialized accordingly (e.g., looking at the teacher and nodding despite thinking about something else). This implies that it might be more difficult to observe inattention in university instructors than in school students and points to a major limitation of the present approach: Observational behavior can only serve as an indicator for the lowest level of attention (alertness, orientation), whereas mental engagement is not accessible to immediate observation. That is, what participants think about and how intensively they engage mentally with the learning content at hand is not accessible to observation (Helmke and Renkl, 1992). Future research might follow up on this by including the perspective of the research subjects, e.g., by means of retrospective interviews. This could help to capture an increased amount of specific differences between the participants.

Despite the observed differences having been rather small and on a primal level (off-task vs on-task), they nevertheless revealed substantial variation throughout the course that could in turn be substantially attributed to differences between participants. In particular, we extended previous research that relied on selfreports (e.g., Daumiller et al., 2020a) by showing that participants' motivations for the current course, in the form of their achievement goals, meaningfully pre- dicted subsequent differences in their observed attention. This constitutes an important stepping stone for our understanding of differences in university instructors' engagement in professional training courses, and, ultimately, why some of them learn more than others. Although we did not investigate participants' learning gains, it can be presumed from theoretical models and empirical findings (Anderson, 1984; Helmke and Renkl, 1992; Imhof, 2004) that attention constitutes a fundamental premise to successful learning processes.

Our findings on learning approach goals confirmed our expectations and are in line with the clearly adaptive pattern of this type of goal pursuit for initiating and sustaining learning and engaging in deep processing strategies (Elliot and McGregor, 2001; Grant and Dweck, 2003; Hulleman et al., 2010), particularly for university instructors (Daumiller et al., 2020a; Hein et al., 2019). However, our hypotheses for performance goals and relational goals were not confirmed. While not many studies have been conducted on the relevance of relational goals for learning processes, there is a plethora of research findings on performance goals being associated with shallow learning and, especially for performance avoidance goals, impaired learning outcomes (Hulleman et al., 2010; Nitsche et al., 2013a; Nitsche et al., 2013b; Payne et al., 2007). Not having found statistically significant negative associations with attention might point to differences between student learners and university instructors in professional training courses: Given that class sizes in schools are much larger than the investigated courses (including on average 9 participants per course), inattentiveness was likely more easily detected. At the same time, given the complexity of the materials to be learned, the participants might have needed to put forth a great deal of attention to understand the materials sufficiently, to avoid appearing incompetent, and to demonstrate high personal competence. These mechanisms might counteract the adverse effects of performance goals on attention and lead to nil effects. Finally, the negative findings of work avoidance goals confirmed our expectations. In contrast to performance goals, this type of goal striving orientates individuals to save personal resources, and as such it is theoretically reasonable that also their attention cannot be fully focused on the resource-intensive learning context at hand. Therefore, this finding entrenches the negative associations of this type of goal for the use of learning opportunities, the employed learning strategies, and learning engagement (Daumiller et al., 2020a; Nitsche et al., 2013a; Nolen, 1988). 
While the effects of learning approach and work avoidance goals are theoretically sensible in that they align with a consistent body of findings on the relevance of these two types of motivations for learning, they also advance this research by documenting that these goals already draw on a fundamental and wellrooted premise of learning engagement (Dijksterhuis and Aarts, 2010; Helmke, 2012; Posner and Fan, 2008; Rothkopf and Billington, 1979). Surprisingly, previous research has not yet examined this link. As such, beyond our understanding of the learning engagement of a specific population, a central theoretical implication of the present research lies in illuminating the role of goals for fundamental learning processes. Given that we focused on general psychological processes, we consider our findings largely generalizable on an international level-despite having studied only university instructors from Germany. In fact, as the sampled instructors participated voluntarily in the professional training courses (which could explain the rather favourable motivations at the beginning of the course as well as the high attention levels), we might expect larger and even clearer effects when conducting similar investigations in other contexts (e.g., where instructors are required to participate in professional training courses, which should create more differences in motivations and attention). Despite this, it is a limitation of faculty motivation research that most studies have focused specific countries and university systems (see Daumiller et al., 2020b). Against this background, future research should investigate cross-cultural perspectives to contribute to a better understanding of the impact of different working environments on university instructors' learning. To this end, we consider it worthwhile to also include subsequent processes and outcomes of the learning process, e.g., knowledge gains (see also Edwards, 2010).

Despite more research on this topic being required, our findings allow for first practical implications to be derived. We conclude that in professional training courses, learning goals should be supported and work avoidance goals should be reduced. To facilitate this, practicioners may seek to directly influence these goals, for example, through stressing the relevance of learning and the respective goals, putting goals into writing, and supporting instructors in dealing with high work load by other means instead of pursuing strong work avoidance goals (e.g., prioritizing, using different resources). Aside from that, goal striving processes should also be supported by arranging contextual features such as learning goal structures that can support individuals in pursuing and maintaining adaptive goals (e.g., Lüftenegger et al., 2014). Taken together, we believe that participants' achievement goals impact their attentiveness and, in consequence, can facilitate more engaged learning in professional training courses.

\section{Notes}

1. In the present study, we focused performance goals on the appearance component (i.e., strivings to make a good/avoid a bad impression; opposed to strivings of wanting to be better or worse than others) in order to be conceptually clear (see Daumiller et al., 2019; Grant \& Dweck, 2003; Hulleman et al., 2010). To this end, we chose performance appearance goals over performance normative goals as we considered them to be possibly more directly related to the immediate behaviors (and, as such, their attention) of participants during the course, whereas performance normative goals might be more strongly tied to the outcomes of the learning activities.

2. ICC2 $>.70=$ Indicator of good evaluator agreement ICC2 stands for intraclass correlation with consistent two raters for all participants.

\section{References}

Aarts, H., Dijksterhuis, A. and De Vries, P. (2001), „On the psychology of drinking: Being thirsty and perceptually ready"; British Journal of Psychology, Vol. 92, pp.631642.https://doi.org/10.1348/000712601162383

Amundsen, C. and Wilson, M. (2012), "Are we asking the right questions?", Review of Educational Research, Vol. 82, pp.90-126. https://doi.org/10.3102/0034654312438409

Anderson, L.W. (1984), "Attention, tasks and time", Anderson, L.W. (Ed.), Time and school learning: Theory, research and practice, Croom Helm, London, UK, pp.46-68.

Baer, R.A., Smith, G.T. and Allen, K.B. (2004), „Assessment of mindfulness by self-report: The Kentucky inventory of mindfulness skills", Assessment, Vol. 11, pp.191-206. https://doi.org/10.1177/1073191104268029

Butler, R. (2012), "Striving to connect", Journal of Educational Psychology, Vol. 104, pp.726-742. https://doi.org/10.1037/a0028613

Crouzevialle, M. and Butera, F. (2013), "Performance-approach goals deplete working memory and impair cognitive performance", Journal of Experimental Psychology: General, Vol. 142, 
pp.666-678.

https://doi.org/10.1037/a0029632.supp

Csikszentmihalyi, M. (2018), "Flow: das Geheimnis des Glücks [Flow: The secret of luck]", KlettCotta, Stuttgart, Germany.

Daniels, J. (2017), "Professional learning in higher education: making good practice relevant", International Journal for Academic Development, Vol. 22, pp.170-181. https://doi.org/10.1080/1360144x.2016.1261352

Darnon, C., Butera, F. and Harackiewicz, J.M. (2007), "Achievement goals in social interactions: Learning with mastery vs. performance goals", Motivation and Emotion, Vol. 31, pp.61-70. https://doi.org/10.1007/s11031-006-9049-2

Daumiller, M. (2018), "Motivation von Wissenschaftlern in Lehre und Forschung [Motivation of university scholars for teaching and research]", Wiesbaden, Germany, Springer VS. https://doi.org/10.1007/978-3-658-21182-0

Daumiller, M., Dickhäuser, O. and Dresel, M. (2019), "University instructors' achievement goals for teaching", Journal of Educational Psychology, Vol. 111, pp.131-148. https://doi.org/10.1037/edu0000271

Daumiller, M. and Dresel, M. (2018), "Subjective perceptions of the teaching-research nexus and occupational stress at universities", Zeitschrift für Entwicklungspsychologie und Pädagogische Psychologie, Vol. 50, pp.126-138.

https://doi.org/10/cwmt

Daumiller, M., Grassinger, R., Dickhäuser, O. and Dresel, M. (2016), "Structure and relationships of university instructors' achievement goals", Frontiers in Psychology, Vol. 7. https://doi.org/10.3389/fpsyg.2016.00375

Daumiller, M., Rinas, R., Olden, D., \& Dresel, D. (2020a), "Academics' motivations in professional training courses: Effects on learning engagement and learning gains.", International Journal of Academic Development. https://doi.org/10.1080/1360144X.2020.1768396

Daumiller, M., Stupnisky, S., \& Janke, S. (2020b), "Motivation of higher education faculty: eoretical approaches, empirical evidence, and future directions [Editorial]", International Journal of Educational Research, Vol. 20. https://doi.org/10.1016/j.ijer.2019.101502.

Diethert, A.P., Weisweiler, S., Frey, D. and Kerschreiter, R. (2015), „Training motivation of employees in academia“", Zeitschrift für Erziehungswissenschaft, Vol. 18, pp.29-50. https://doi.org/10.1007/s11618-014-0596-0

Dijksterhuis, A. and Aarts, H. (2010), „Goals, attention, and (un)consciousness", Annual Review of Psychology, Vol. 61, pp.467-490. https://doi.org/10.1146/annurev.psych.093008.100445

Dodd-McCue, D. and Tartaglia, A. (2010), "Self-report response bias: learning how to live with its diagnosis in chaplaincy research", Chaplaincy Today, Vol. 26, pp.2-8. https://doi.org/10.1080/10999183.2010.10767394

Edwards, O.V. (2010), "The effect of goal orientation of attention, learning, and metacognitive awareness", UNLV Theses, Dissertations, Professional Papers, and Capstones, Vol. 261. https://digitalscholarship.unlv.edu/thesesdissertations/261

Elliot, A.J. (1999), "Approach and avoidance motivation and achievement goals", Educational Psychologist, Vol. 34, pp.169-189. doi.org/10.1207/s15326985ep3403_3

Elliot, A.J. (2005), "A conceptual history of the achievement goal construct", Elliot, A. (Ed.), Handbook of Competence and Motivation, Guilford, New York, NY, pp.52-72.

Elliott, E.S. and Dweck, C.S. (1988), „Goals: An approach to motivation and achievement", Journal of Personality and Social Psychology, Vol. 54, pp.512. https://doi.org/10.1037/0022-3514.54.1.5

Elliot, A.J. and McGregor, H.A. (2001), "A $2 \times 2$ achievement goal framework", Journal of Personality and Social Psychology, Vol. 80, pp.501-516. https://doi.org/10.1037/0022-3514.80.3.501

Fisher, C.W., Berliner, D.C., Filby, N.N., Marliave, R., Cahen, L.S. and Dishaw, M.M. (1980), "Teaching behaviors, adacemic learning time, and student achievement: An overview", Denham, C. and Lieberman, A. (Eds.), Time to Learn, National Institute of Education, Washington, DC, pp.7-32.

Fredericks, J.A., Blumenfeld, P.C. and Paris, A.H. (2004), "School engagement: Potential of the concept, state of the evidence", Review of Educational Research, Vol. 74, pp.59-109. https://doi.org/10.3102/00346543074001059

Gazzaley, A. and Nobre, A.C. (2012), “Top-down modulation: Bridging selective attention and working memory", Trends in Cognitive Sciences, Vol. 16, pp.129-135. doi.org/10.1016/j.tics.2011.11.014

Gerken, M., Beausaert, S. and Segers, M. (2015), "Working on professional development of faculty 
staff in higher education: Investigating the relationship between social informal learning activities and employability", Human Resource Development International, Vol. 19, pp.135-151. https://doi.org/10.1080/13678868.2015.1116241

Goleman, D. (2013), Focus: The hidden driver of excellence, Harper Collins, New York, NY.

Grant, H. and Dweck, C. (2003), "Clarifying achievement goals and their impact", Journal of Personality and Social Psychology, Vol. 85, pp.541-553. https://doi.org/10.1037/0022-3514.85.3.54.

Hein, J., Daumiller, M., Janke, S., Dresel, M. and Dickhäuser, O. (2019), "How learning time mediates the impact of university scholars' learning goals on professional learning in research and teaching", Learning and Individual Differences, Vol. 72, pp.15-25. https://doi.org/10.1016/j.lindif.2019.04.002

Helmke, A. and Schrader, F.-W. (1998), "Entwicklung im Grundschulalter [Development in primary education age]“, Pädagogik, Vol. 50, No. 6, pp.2530.

Helmke, A. (1988), Das Münchener Aufmerksamkeitsinventar (MAI) [The Munic Attention Inventory (MAI)], Max-Planck-Institut für psychologische Forschung, München, Germany.

Helmke, A. (2012), Unterrichtsqualität und Lehrerprofessionalität [Teaching quality and teacher professionality], Klett-Kallmeyer, Seelze, Germany.

Helmke, A. and Renkl, A. (1992), „Das Münchener Aufmerksamkeitsinventar (MAI) [The Munic Attention Inventory (MAI)]“, Diagnostica, Vol. 38, No. 2, pp.130-141.

Hessing, D.J., Elffers, H. and Weigel, R.H. (1988), "Exploring the limits of self-reports and reasoned action: an investigation of the psychology of tax evasion behavior", Journal of Personality and Social Psychology, Vol. 54, pp.405-413. https://doi.org/10.1037//0022-3514.54.3.405

Hommel, M. (2012a). Aufmerksamkeitsverhalten und Lernerfolg - eine Videostudie [Attention behavior and learning success - a video study], Europäische Hochschulschriften. Reihe XI Pädagogik, Bd.Nol. 1023, Frankfurt am Main, Berlin, Bruxelles, Oxford, Wien: Peter Lang.

Hommel, M. (2012b), „Kodierhandbuch des Beobachtungsinventars zur systematischen und videobasierten Erfassung der Aufmerksamkeit von Lernenden $(\mathrm{m} / \mathrm{w})$. Modifiziertes Aufmerksamkeitsinventar (ModAI) [Coding manual for the observation inventory for systematic and video based recording of attention of learners. Modified Attention Inventory (ModAI)]", TU Dresden (Ed.), Dresdner Beiträge zur Wirtschaftspädagogik, TU Dresden, Dresden, Germany, pp.1-69.

Hulleman, C., Schrager, S., Bodmann, S. and Harackiewicz, J. (2010), „A meta-analytic review of achievement goal measures", Psychological Bulletin, Vol. 136, pp.422-449. https://doi.org/10.1037/a0018947

Hurtz, G.M. and Williams, K.J. (2009), “Attitudinal and motivational antecedents of participation in voluntary employee development activities", Journal of Applied Psychology, Vol. 94, pp.635-653. https://doi.org/10.1037/a0014580

Imhof, M. (2004), ,Diagnostik von Konzentration und Aufmerksamkeit in der Schule [Diagnosis of concentration and attention at school]", Büttner, G. and Schmidt-Atzert, L. (Eds.), Diagnostik von Konzentration und Aufmerksamkeit, Hogrefe, Göttingen, Germany. pp.233-248.

Kaspar, K. and König, P. (2011), "Overt attention and context factors: the impact of repeated prestentations, image type, and individual motivation", PloS one, Vol. 6. https://doi.org/10.1371/journal.pone.0021719

Korn, R.M., Elliot, A.J. and Daumiller, M. (2019), "Back to the roots: the $2 \times 2$ standpoints and standards achievement goal model", Learning and Individual Differences, Vol. 72, pp.92-102. https://doi.org/10.1016/j.lindif.2019.04.009

Lüftenegger, M., Van de Schoot, R., Schober, B., Finsterwald, M. and Spiel, C. (2014), "Promotion of students' mastery goal orientations: Does TARGET work?", Educational Psychology, Vol. 34, pp.451-469. https://doi.org/10.1080/01443410.2013.814189

Moskowitz, G.B. (2002), "Preconscious effects of temporary goals on attention", Journal of Experimental Social Psychology, Vol. 38, pp.397-404. https://doi.org/10.1016/S0022-1031(02)00001-X

Murayama, K. and Elliot, A.J. (2011), "Achievement motivation and memory", Personality and Social Psychology Bulletin, Vol. 37, pp.1339-1348. https://doi.org/10.1177/0146167211410575

Muthén, L.K. and Muthén, B.O. (2017), "Mplus (Version 8) [Computer Software]", Muthén \& Muthén, Los Angeles, CA.

Neumann, O. (1996), "Theories of attention", Neumann, O. and Sanders, A.F. (Eds.), Handbook of Perception and Action, Academic Press, London, England, pp.389-446. 
Neumann, A. (2009). Professing to learn: creating tenured lives and careers in the American research university, Johns Hopkins University Press, Baltimore, MD.

Nitsche, S., Dickhäuser, O., Dresel, M. and Fasching, M.S. (2013a), "Zielorientierungen von Lehrkräften als Prädiktoren lernrelevanten Verhaltens [Goal orientations of teachers as predictors for learning behavior]", Zeitschrift für Pädagogische Psychologie, Vol. 27, pp.95-103. https://doi.org/10.1024/1010-0652/a000092

Nitsche, S., Dickhäuser, O., Fasching, M.S. and Dresel, M. (2013b), “Teachers' professional goal orientations: Importance for further training and sick leave", Learning and Individual Differences, Vol. 23, pp.272-278. https://doi.org/10.1016/j.lindif.2012.07.017

Nolen, S.B. (1988), "Reasons for studying: Motivational orientations and study strategies", Cognition and Instruction, Vol. 5, pp.269-287. https://doi.org/10.1207/s1532690xci0504_2

Ocasio, W. (1997), "Towards an attention-based view of the firm", Strategic Management Journal, Vol. 18, pp.187-206.

Ocasio, W. (2011), “Attention to attention”, Organization Science, Vol. 22, pp.1286-1296. https://doi.org/10.1287/orsc.1100.0602

Payne, S.C., Youngcourt, S.S. and Beaubien, J.M. (2007), "A meta-analytic examination of the goal orientation nomological net", The Journal of Applied Psychology, Vol. 92, pp.128-150. https://doi.org/10.1037/0021-9010.92.1.128

Posner M.I. and Fan, J. (2008), "Attention as an organ system", Pomerantz, J.R. (Ed.), Topics in Integrative Neuroscience: From Cells to Cognition, University Press, Cambridge, England, pp.31-61.

Rosenshine, B.V. and Stevens, R. (1986), "Teaching functions", Wittrock, M.C. (Ed.), Handbook of Research on Teaching, MacMillan, New York, NY, pp.376-391.

Rothkopf, E.Z. and Billington, M.J. (1979), "Goalguided learning from text", Journal of Educational Psychology, Vol. 71, pp.310-327. https://doi.org/10.1037//0022-0663.71.3.310

Saroyan, A. and Trigwell, K. (2015), "Higher education teachers' professional learning", Studies in Educational Evaluation, Vol. 46, pp.92-101. https://doi.org/10.1016/j.stueduc.2015.03.008

Savage, T.V. and Savage, M.K. (2010), Successful classroom management and discipline: teaching self-control and responsibility, Sage, Los Angeles, CA.
Scholkmann, A., Siemon, J. and Boom, K.-D. (2017), "Time on task during game-based learning", Zeitschrift für Erziehungswissenschaft, Vol. 20, pp.651-669. https://doi.org/10.1007/s11618-017$0736-4$

Senko, C. and Dawson, B. (2016), "Performance-approach goal effects depend on how they are defined", Journal of Educational Psychology, Vol. 109, pp.574-598. https://doi.org/10.1037/edu0000160

Svinicki, M.D. and McKeachie, W.J. (2014), McKeachie's teaching tips, Wadsworth Cengage Learning, Belmond, CA.

Terosky, A.L. and Gonzales, L.D. (2016), "Scholarly learning as vocation", Innovative Higher Education, Vol. 41, pp.105-120. https://doi.org/10.1007/s10755-015-9341-8

Thadani, V., Breland, W. and Dewar, J. (2015), "Implicit theories about teaching skills predict university faculty members' interest in professional learning", Learning and Individual Differences, Vol. 40, pp.163-169. https://doi.org/10.1016/j.lindif.2015.03.026

van Eekelen, I.M., Boshuizen, H.P. and Vermunt, J.D. (2005), "Self-regulation in higher education teacher learning", Higher Education, Vol. 50, pp.447-471. https://doi.org/10.1007/s10734-0046362-0

Webster-Wright, A. (2009), "Reframing professional development through understanding authentic professional learning", Review of Educational Research, Vol. 79, pp.702-739. https://doi.org/10.3102/0034654308330970

\footnotetext{
Acknowledgements: We thank Christian Eibl and Susanne Reeß for their help in conducting the study, and Raven Rinas for her help in proofreading the paper.

Author contributions: M.Dr. and M.Da. conceived of the presented idea. B.K., M.Dr., and M.Da. planned the study. B.K. was in charge of data collection and had full access to all the data in the study and takes full responsibility for the integrity of the data and the accuracy of the data analysis. B.K. and M.Da. drafted the article. M.Dr. and M.Da. provided critical revision of the article for important intellectual content. M.Dr. and M.Da. provided administrative, technical, and material support. All authors approved of the version to be published.

Note: This is a pre-copyedited, author-produced PDF of an article accepted for publication in Higher Education, Skills and Work-based Learning following peer review. This paper is not the copy of record and may not exactly replicate the final, authoritative version of the article. The final article will be available, upon publication, via its DOI.
} 